\title{
Screening of Inhibition of Calcium Naphthenate Deposition in Crude Oil
}

Sébastien SIMON*, Kim EHRET, Pauline DARCEL, Johan SJÖBLOM

Ugelstad Laboratory, Department of Chemical Engineering, the Norwegian University of Science and Technology (NTNU), N-7491 Trondheim, Norway

\section{Nicolas PASSADE-BOUPAT}

TOTAL S.A., PERL - Pôle D’Etudes et de Recherche de Lacq, 64170 Lacq, France

\section{Thierry PALERMO}

TOTAL S.A., CSTJF - Centre Scientifique et Technique Jean Féger, 64018 Pau, France

\section{Supporting materials}
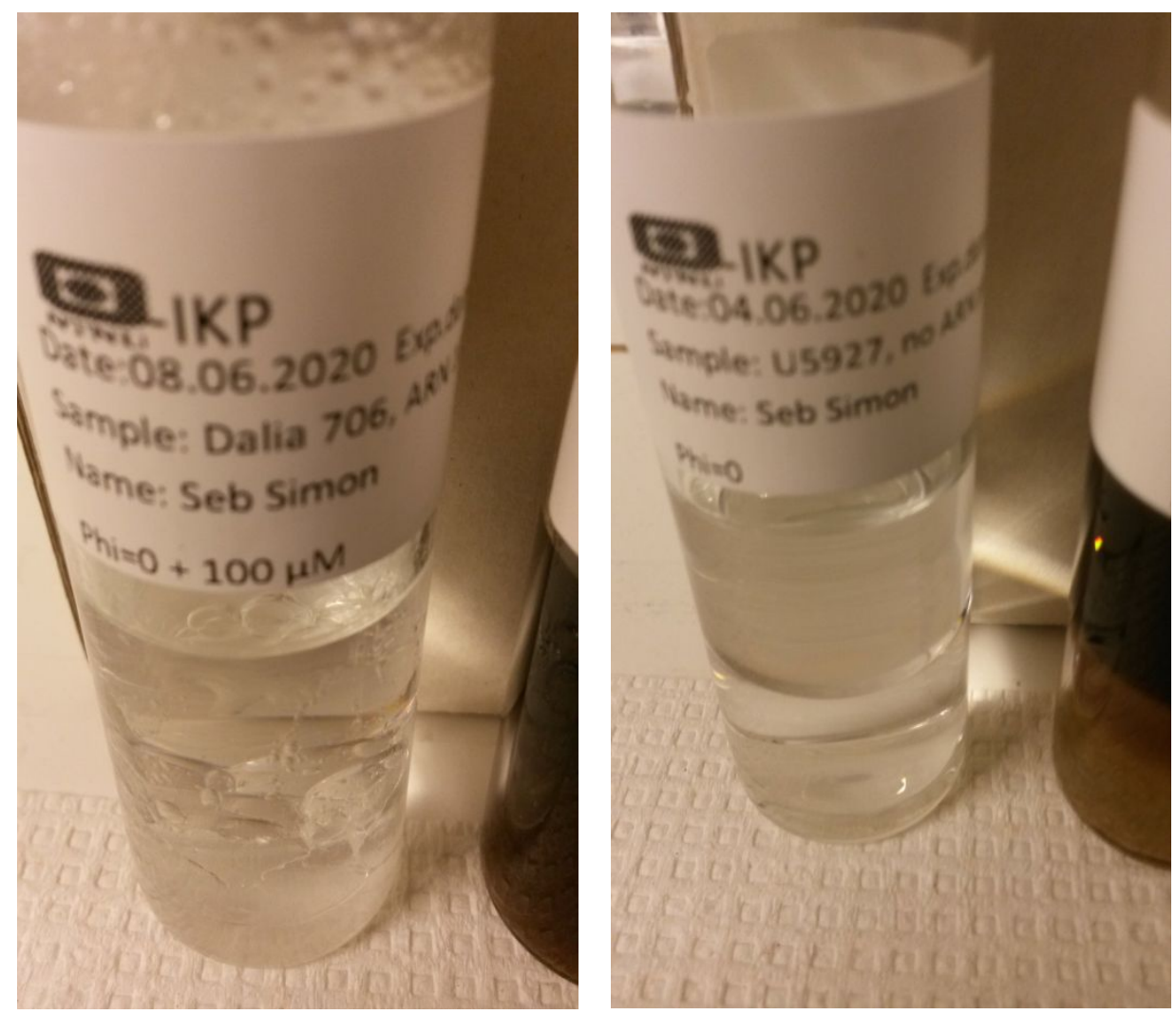

Figure S1: Aspect of mixtures of xylene solutions containing no (right) or $100 \mu \mathrm{M}$ ARN and aqueous phases after shaking overnight. The samples contain no crude oil. 

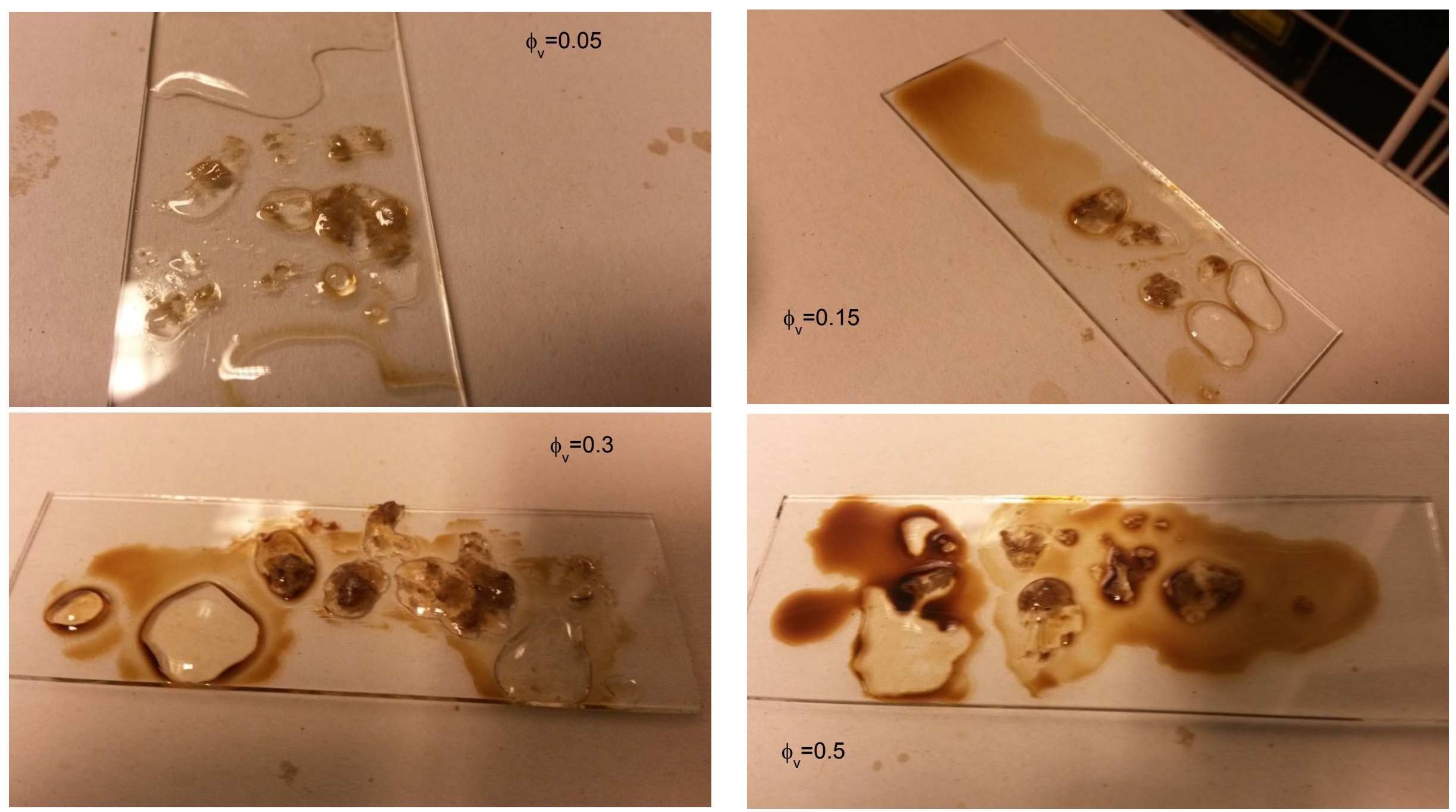

Figure S2: Material recovered from the wall of the centrifugation tube for crude oil $U$ at various volume fractions $\phi_{v}(0.05,0.15,0.3$, and 0.5$)$ in presence of $100 \mu \mathrm{M}$ of ARN and transferred on a microscope slide. 

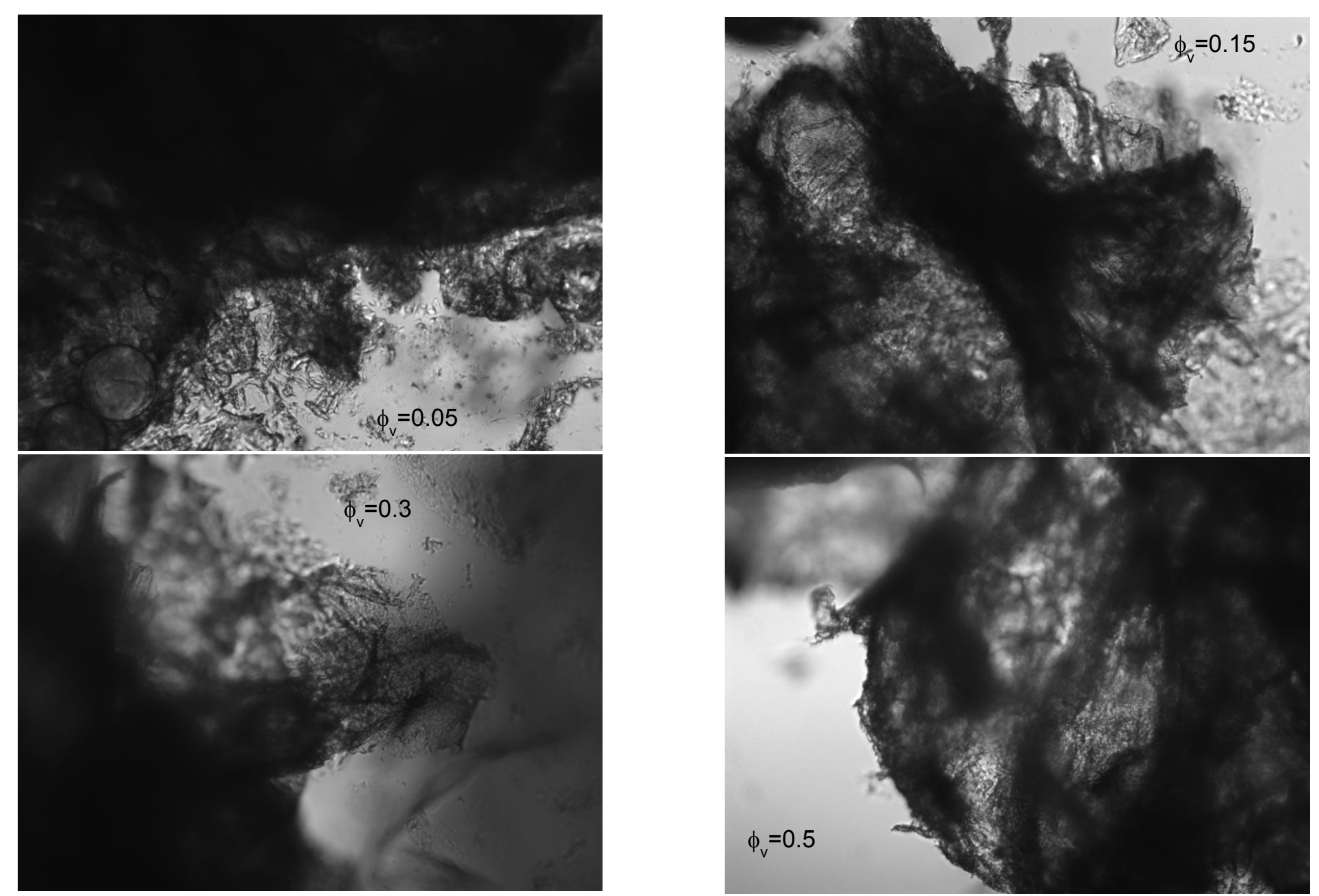

Figure S3: Material recovered from the wall of the centrifugation tube for crude oil $U$ at various volume fractions $(0.05,0.15,0.3$, and 0.5$)$ in presence of 100 $\mu \mathrm{M}$ of ARN and transferred on a microscope slide. Dimensions of the picture: $647 \times 479 \mu \mathrm{m}$. 

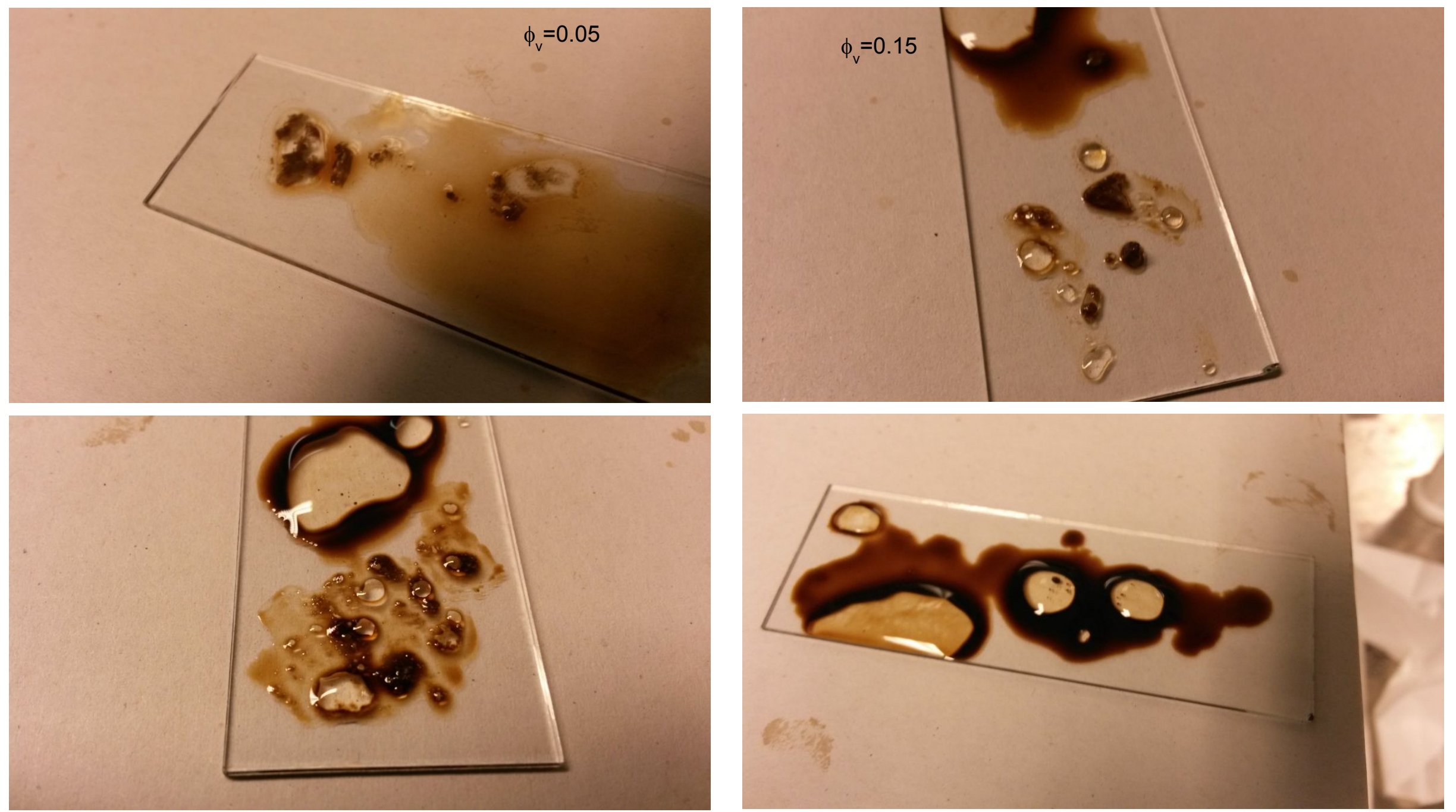

Figure S4: Material recovered from the wall of the centrifugation tube for crude oil $D$ at various volume fractions $(0.05,0.15,0.3$, and 0.5$)$ in presence of 100 $\mu \mathrm{M}$ of ARN and transferred on a microscope slide. 

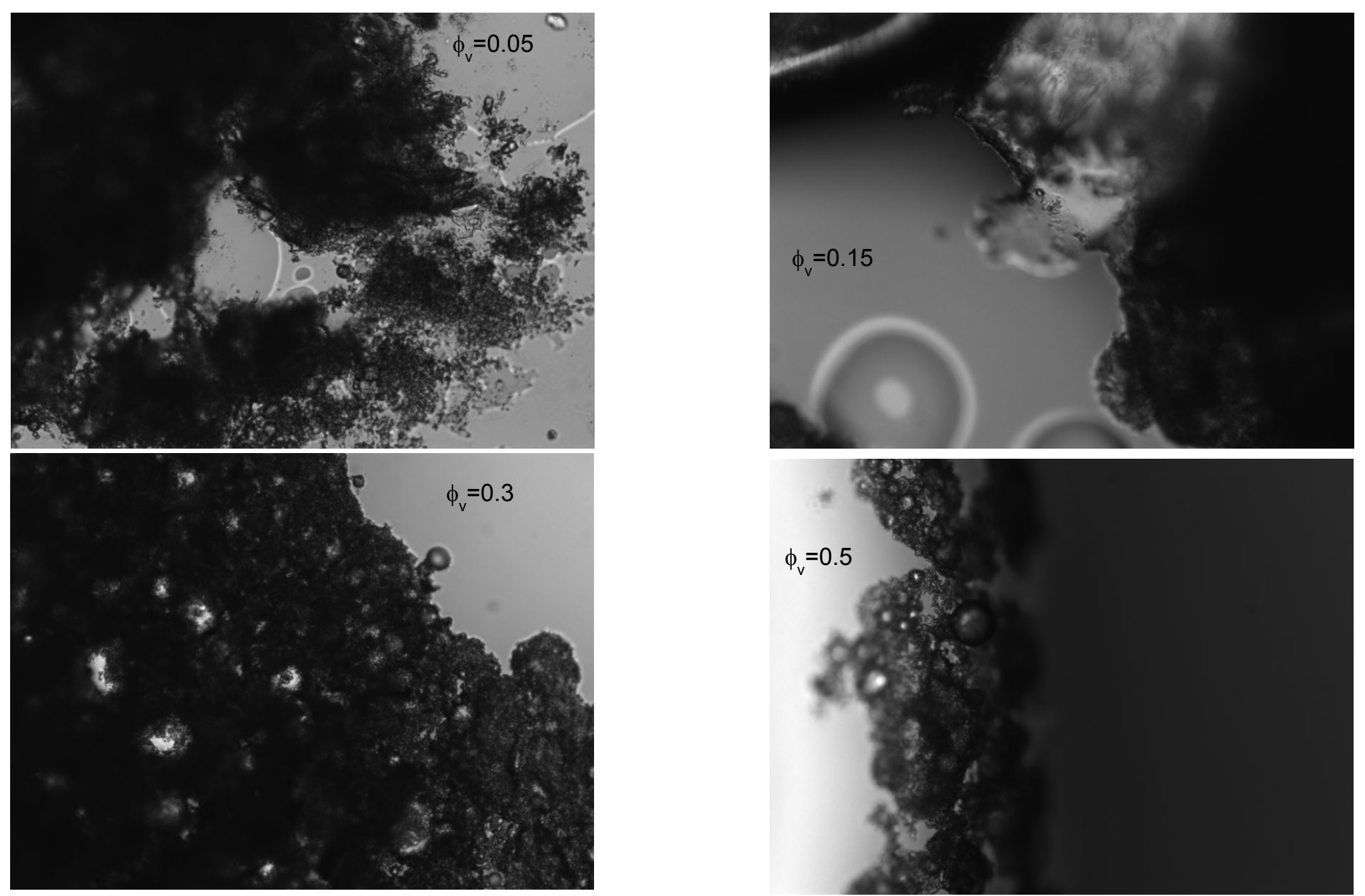

Figure S5: Material recovered from the wall of the centrifugation tube for crude oil $D$ at various volume fractions $(0.05,0.15,0.3$, and 0.5$)$ in presence of 100 $\mu \mathrm{M}$ of ARN and transferred on a microscope slide. Dimensions of the picture: $647 \times 479 \mu \mathrm{m}$. 

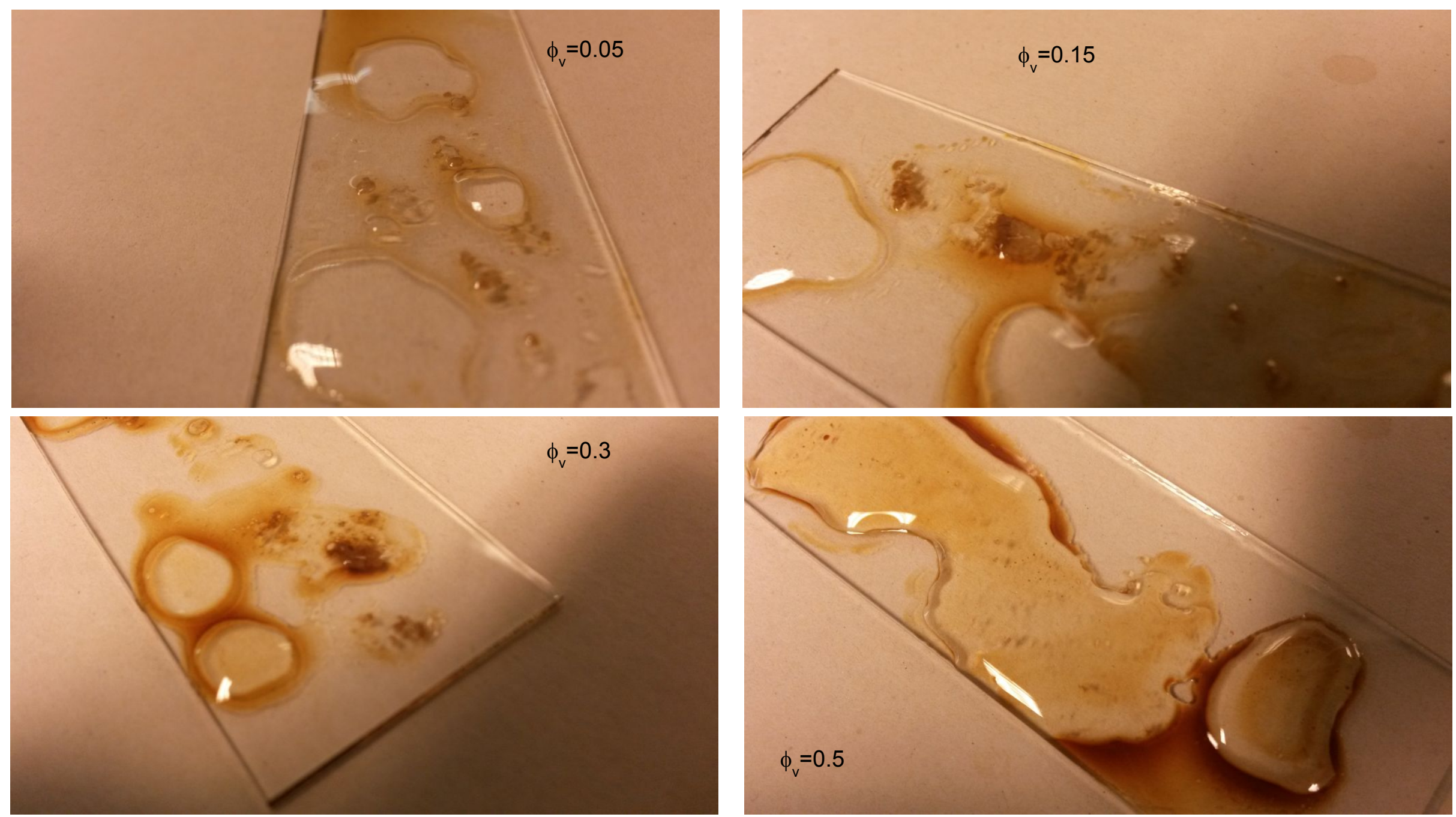

Figure S6: Material recovered from the wall of the centrifugation tube for crude oil $E$ at various volume fractions $(0.05,0.15,0.3$, and 0.5$)$ in presence of 100 $\mu \mathrm{M}$ of ARN and transferred on a microscope slide. 

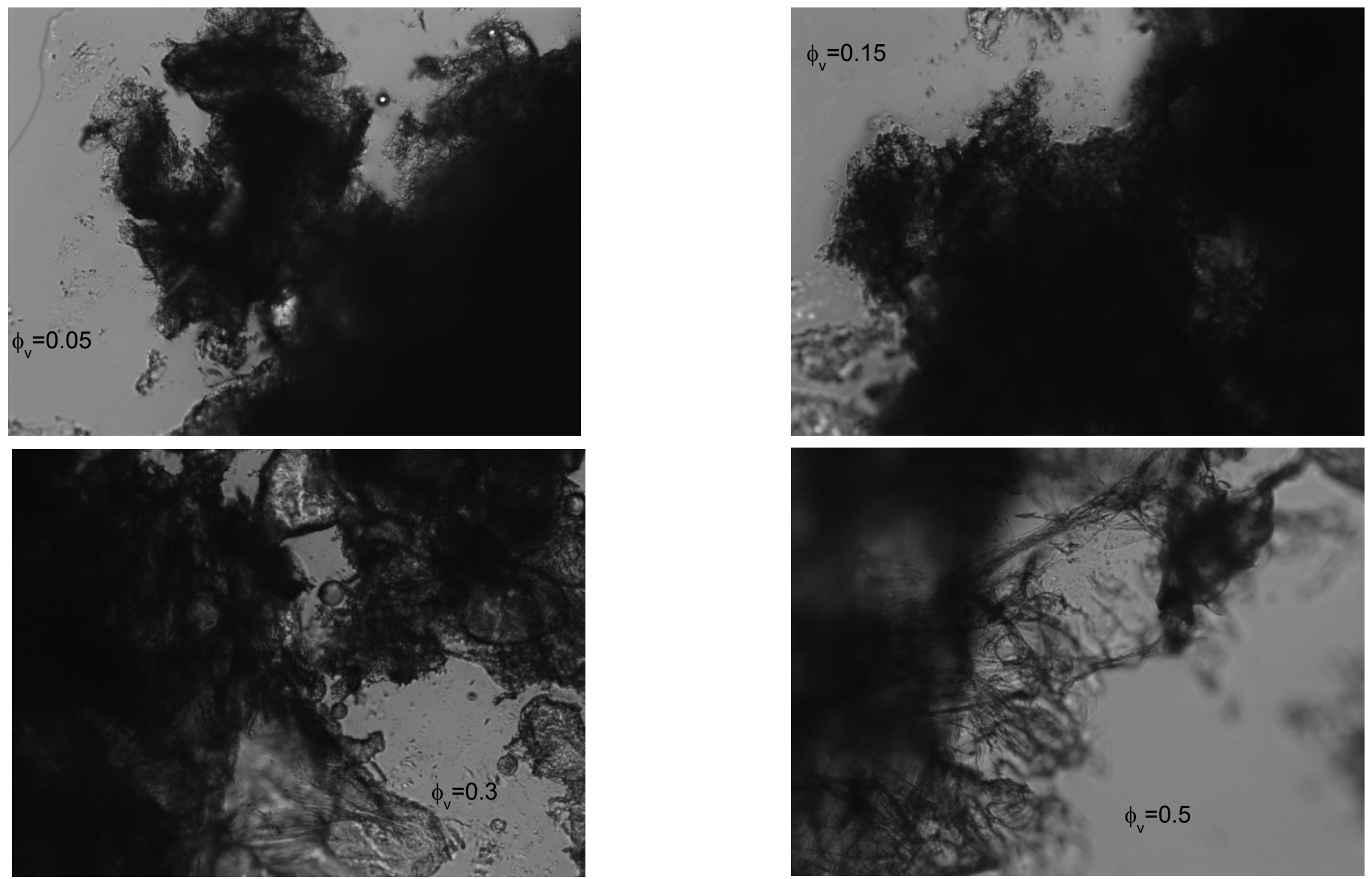

Figure S7: Material recovered from the wall of the centrifugation tube for crude oil $E$ at various volume fractions $(0.05,0.15,0.3$, and 0.5$)$ in presence of 100 $\mu \mathrm{M}$ of ARN and transferred on a microscope slide. Dimensions of the picture: $647 \times 479 \mu \mathrm{m}$. 

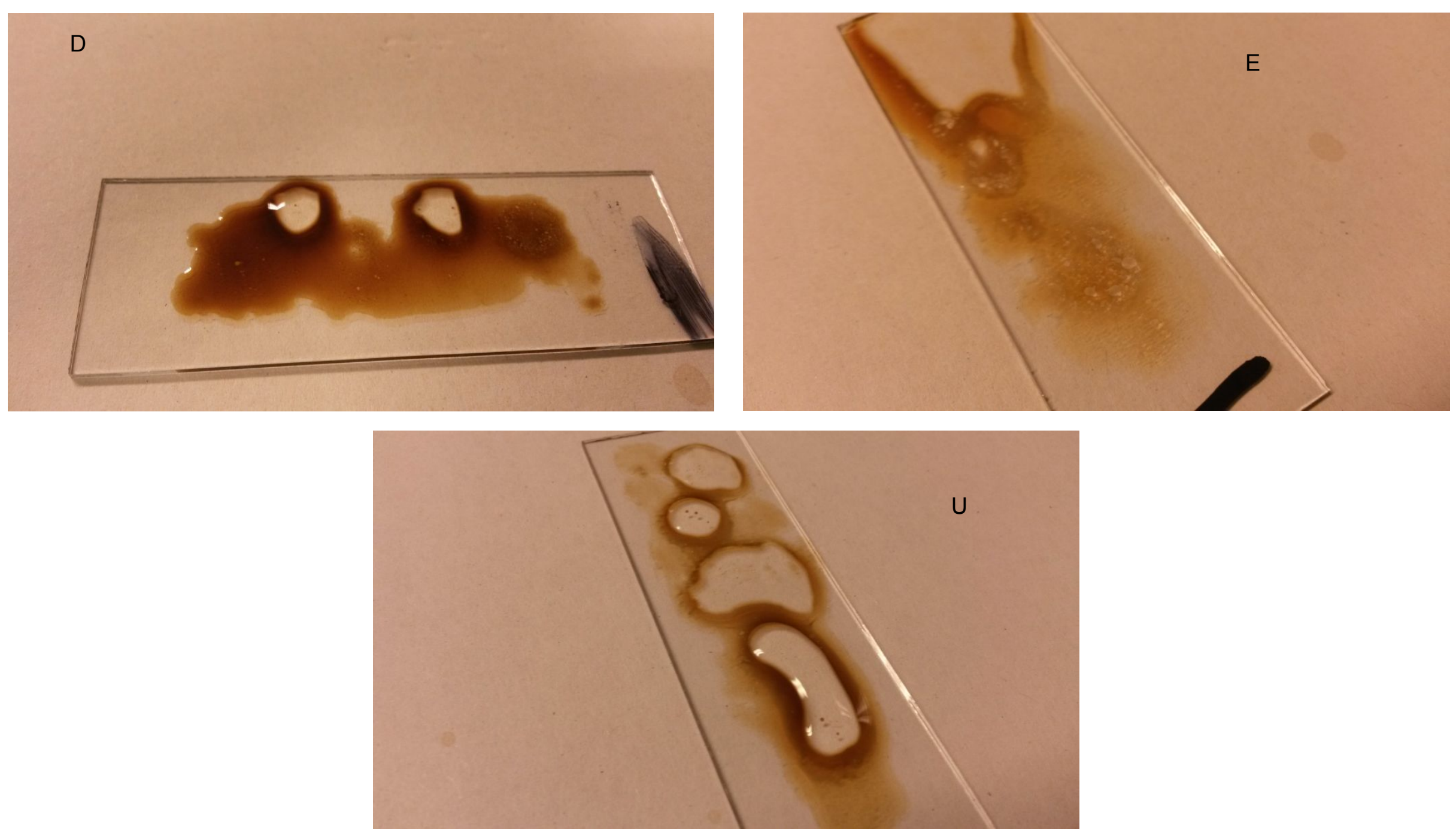

Figure S8: Material recovered from the wall of the centrifugation tube for crude oils $D, E$, and $U$ at a volume fraction of 0.15 in absence of ARN and transferred on a microscope slide. 

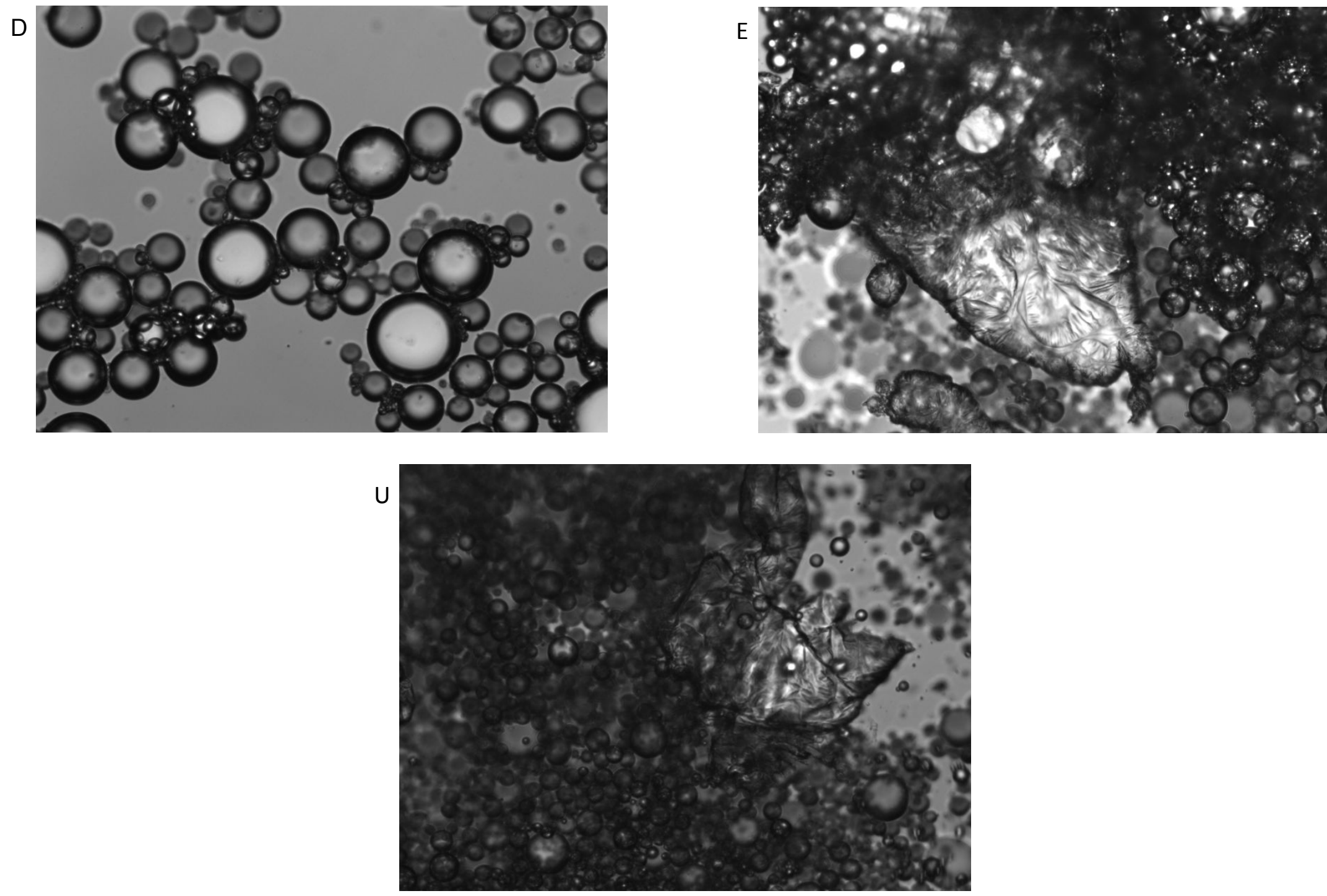

Figure S9: Microscope pictures of the crude oils D, E, and $U$ at a volume fraction of 0.15 in absence of ARN and transferred on a microscope slide. Dimensions of the picture: $647 \times 479 \mu \mathrm{m}$. 